E3S Web of Conferences 1, 16003 (2013)

DOI: $10.1051 / \mathrm{e} 3$ sconf/20130116003

(c) Owned by the authors, published by EDP Sciences, 2013

\title{
Partitioning and Dissolution Behavior of Metal-based Engineered Nanoparticles in Sediment and Soil Suspensions
}

\author{
F. Van Koetsem ${ }^{1}$ and G. Du Laing ${ }^{2}$ \\ ${ }^{1}$ Laboratory of Analytical Chemistry and Applied Ecochemistry, Department of Applied Analytical and Physical \\ Chemistry, Faculty of Bioscience Engineering, Ghent University, Coupure Links 653, Ghent, BELGIUM, \\ Frederik.VanKoetsem@UGent.be \\ ${ }^{2}$ Laboratory of Analytical Chemistry and Applied Ecochemistry, Department of Applied Analytical and Physical \\ Chemistry, Faculty of Bioscience Engineering, Ghent University, Coupure Links 653, Ghent, BELGIUM,
}

Gijs.DuLaing@UGent.be

\begin{abstract}
Nowadays engineered nanoparticles are being used in a whole range of commercial applications and are therefore expected to inevitably find their way into the environment where their fate and behavior are still largely unknown. The objective of this study was to investigate the behavior and fate of a number of engineered nanoparticles $\left(\mathrm{CeO}_{2}, \mathrm{SnO}_{2}, \mathrm{Ag}\right)$ in sediment and soil suspensions. In particular, the association of nanoparticles with solid phases, the kinetics of these interactions, and the solubility of the nanoparticulate matter in sediment and soil suspensions were studied. Four different sediments and three different soils were sampled at various locations in Flanders (Belgium), dried, grinded and characterized. Sediment and soil suspensions were prepared with Milli-Q water $(1 / 10 \mathrm{~S} / \mathrm{L})$, spiked with the different metallic nanoparticles or corresponding ions, and continuously shaken for 24 hours. At regular time intervals, samples of the suspensions were collected and centrifuged at 500 or $2000 \mathrm{rpm}$, or left for gravitational settling. The supernatant was analyzed for total metal contents after aqua regia digestion and for dissolved metal ions after centrifugal ultrafiltration. In a second experiment, the impact of centrifugation speed on the amount of suspended matter in the supernatant was also studied. Relations between soil or sediment properties, suspended matter and metals in the supernatant were investigated. First data already point towards a strong association of nanoparticles with suspended material. The remaining data are still being collected and will be presented at the conference.
\end{abstract}

Key words: Nanoparticles, partitioning, sediment, soil, metal, dissolution

\section{Introduction}

The increasing production and commercial use of engineered nanoparticles (ENPs) will inevitably lead to their (unintentional) release into terrestrial and aquatic environments (Handy et al., 2008). Due to their small sizes these nanoparticles can exhibit a variety of physicochemical properties that differ significantly from their bulk counterparts, and can hence pose a potential threat to human health and ecosystems (Darlington et al., 2009). Therefore, extended knowledge of their environmental behavior and fate is essential in order to assess possible exposure routes and improve risk assessment (Fang et al., 2009).

Partitioning of ENPs between liquid and solid phases as well as their dissolution behavior in complex environmental media can provide important information on their mobility, bioavailability and toxicity. Association of NPs with solid phase compartments will result in limited mobility and therefore render them less bioaccessible (Gimbert et al., 2007).

In this study we aim to contribute in the identification of factors that can influence the interaction of different nanoparticulate materials $\left(\mathrm{CeO}_{2} \mathrm{NPs}, \mathrm{SnO}_{2}\right.$ NPs, Ag NPs) with sediment and/or soil constituents. Partitioning kinetics of NPs between solid and liquid phases and dissolution behavior are investigated, as well as how they are affected by soil and sediment properties.

\section{Materials and Methods}

Sediment samples $(0-30 \mathrm{~cm})$ were collected from four different locations along the river Scheldt (Belgium). Moreover, three different soil samples $(0-20 \mathrm{~cm})$ were 
obtained in the vicinity of the Ghent region. All sediment and soil samples were air-dried at $25^{\circ} \mathrm{C}$. Additionally, the sediment samples were further dried in an oven at 65 ${ }^{\circ} \mathrm{C}$. Afterwards, the different sediment and soil samples were crushed and/or grinded if necessary and passed through a $2 \mathrm{~mm}$ sieve ( $1 \mathrm{~mm}$ in case of sediments). Sediment and soil properties (e.g., pH, EC, CEC, \%OM) were determined according to standard methods (Van Ranst et al., 1999).

$\mathrm{CeO}_{2}, \quad \mathrm{SnO}_{2}$, and $\mathrm{Ag}$ nanoparticle aqueous dispersions were purchased from PlasmaChem Gmbh (Berlin, Germany). Cerium, tin, and silver standard solutions were either obtained from ChemLab NV (Zedelgem, Belgium) or from Merck KGaA (Darmstadt, Germany).

Sediment and soil supensions were prepared with Milli-Q water (EMD Millipore Corp., MA, USA) in a $1 / 10$ ratio $(\mathrm{S} / \mathrm{L})$ and spiked with a known amount of nanoparticles (NPs) or ions. Blank and control samples were also included in the set-up. The suspensions were covered with parafilm and left shaking on a shaking plate for 24 hours. Aliquots were taken in between at designated times. Part of these aliquots was directly digested with aqua regia prior to (pseudo) total elemental analysis via ICP-OES. The other part was subjected to gravitational settling for 10 minutes or centrifugation at different centrifugation speeds (500 and $2000 \mathrm{rpm}$ ) for 10 minutes. Part of the resulting supernatant was analyzed with ICP-OES after aqua regia digestion, while another part was subjected to centrifugal ultrafiltration (UF) followed by ICP-OES analysis to investigate NP dissolution behaviour.

The impact of centrifugation speed on the amount of suspended matter in the supernatant was studied in a second experiment. In this experiment, sediment and soil suspensions were prepared by adding $30,0 \mathrm{~mL}$ of Milli-Q water to $3,000 \mathrm{~g}$ of sediment or soil in a $50 \mathrm{~mL}$ centrifuge tube. These suspensions were shaken thoroughly for at least 30 mins. before being subjected to centrifugation for 10 minutes at different chosen speeds. Afterwards, the centrifuged samples were gently placed onto a steady horizontal surface to not disturb the sample, and 20,0 mL of the supernatant was pipetted with an electronic pipette into proper pre-dried and pre-weighed disposable aluminum evaporation dishes. Finally, the concentration of sediment or soil still present in solution (i.e., in the supernatant) was determined in function of centrifugation speed, by determining the weight remaining inside the evaporation recipients after drying in an oven at $105{ }^{\circ} \mathrm{C}$ for at least 6 hours.

\section{Results and Discussion}

The sediment and soil samples differ significantly in properties. A selection of sediment and soil properties is presented in Table 1.

The impact of centrifugation speed on the amount of material in suspension is presented in Figure 1. The percentage of suspended matter staying in suspension after centrifugation often exceeds 2,5 \% when the samples are subjected to gravitational settling. At a centrifugation speed of $500 \mathrm{rpm}$ this percentage often still exceeds $1 \%$, whereas it becomes low and independent of the centrifugation speed above $1000 \mathrm{rpm}$. The amount of suspended matter in suspension is higher in sediment suspensions compared to soil suspensions.

Cerium concentrations measured in the supernatant two hours after spiking the sediment suspensions with $\mathrm{CeO}_{2}$ nanoparticles and $\mathrm{Ce}$ ions are presented in Figure 2. From these preliminary data, it can already be concluded that association of the particles with the sediments depends on the sediment properties. Moreover, $\mathrm{Ce}$ concentrations are related to the amount of suspended matter in suspension as determined by the centrifugation speed. This suggests a strong association of the $\mathrm{CeO}_{2}$ nanoparticles with suspended matter. However, Ce concentrations in the supernatant are always higher when $\mathrm{CeO}_{2}$ nanoparticles are spiked compared to when $\mathrm{Ce}$ ions are spiked. This suggests that the ions bind more strongly to suspended particles compared to the nanoparticles. Ultracentrifugation data, as well as data for the soils and the other types of nanoparticles are currently still being analysed. Moreover, relationships between soil/sediment properties and fate of the nanoparticles will be assessed. These data will also be presented at the conference.

Table 1. Selected properties of sediment and soil samples (mean $\pm \mathrm{SD}, \mathrm{n}=3$ ).

\begin{tabular}{|c|c|c|c|c|c|}
\hline Sample & $\begin{array}{c}\mathrm{pH}-\mathrm{H}_{2} \mathrm{O} \\
(-)\end{array}$ & $\begin{array}{c}\mathrm{EC} \\
\left(\mu \mathrm{S} \mathrm{cm}^{-1}\right)\end{array}$ & $\begin{array}{c}\text { CEC } \\
\left(\text { meq } 100 \mathrm{~g} \mathrm{DM}^{-1}\right)\end{array}$ & $\begin{array}{l}\text { OM } \\
(\%)\end{array}$ & $\begin{array}{c}\mathrm{CaCO}_{3} \\
(\%)\end{array}$ \\
\hline Sediment A & $7,89 \pm 0,06$ & $1929 \pm 26$ & $10,72 \pm 0,10$ & $4,75 \pm 0,10$ & $14,33 \pm 0,98$ \\
\hline Sediment B & $7,88 \pm 0,02$ & $864 \pm 8$ & $12,56 \pm 0,19$ & $5,08 \pm 0,05$ & $15,22 \pm 0,50$ \\
\hline Sediment C & $7,56 \pm 0,02$ & $961 \pm 14$ & $9,50 \pm 0,00$ & $3,47 \pm 0,04$ & $10,10 \pm 0,76$ \\
\hline Sediment D & $7,55 \pm 0,03$ & $930 \pm 11$ & $24,28 \pm 0,19$ & $9,35 \pm 0,13$ & $10,17 \pm 0,50$ \\
\hline Soil I & $4,52 \pm 0,01$ & $113 \pm 1$ & $8,67 \pm 0,71$ & $3,68 \pm 0,07$ & $3,87 \pm 0,09$ \\
\hline Soil II & $7,53 \pm 0,07$ & $229 \pm 2$ & $9,27 \pm 0,25$ & $3,11 \pm 0,01$ & $4,60 \pm 0,03$ \\
\hline Soil III & $7,06 \pm 0,01$ & $170 \pm 3$ & $8,49 \pm 0,26$ & $4,61 \pm 0,19$ & $2,51 \pm 0,25$ \\
\hline
\end{tabular}




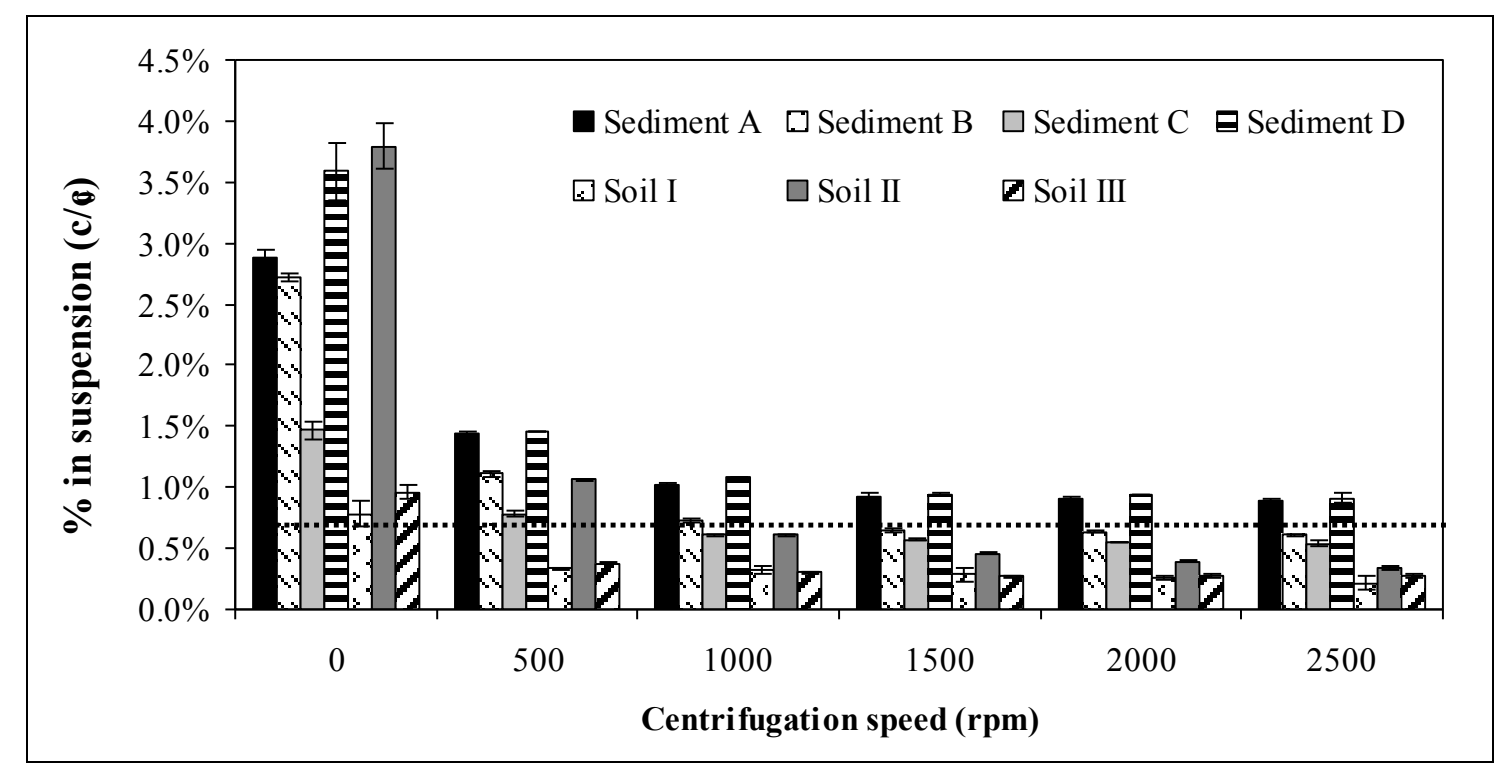

Figure 1. Amount of suspended matter in suspension as affected by centrifugation speed, after centrifuging for 10 minutes. The speed of $0 \mathrm{rpm}$ represents 10 minutes of gravitational settling (bars indicate mean values, error bars represent $\mathrm{SD}, \mathrm{n}=4$ )

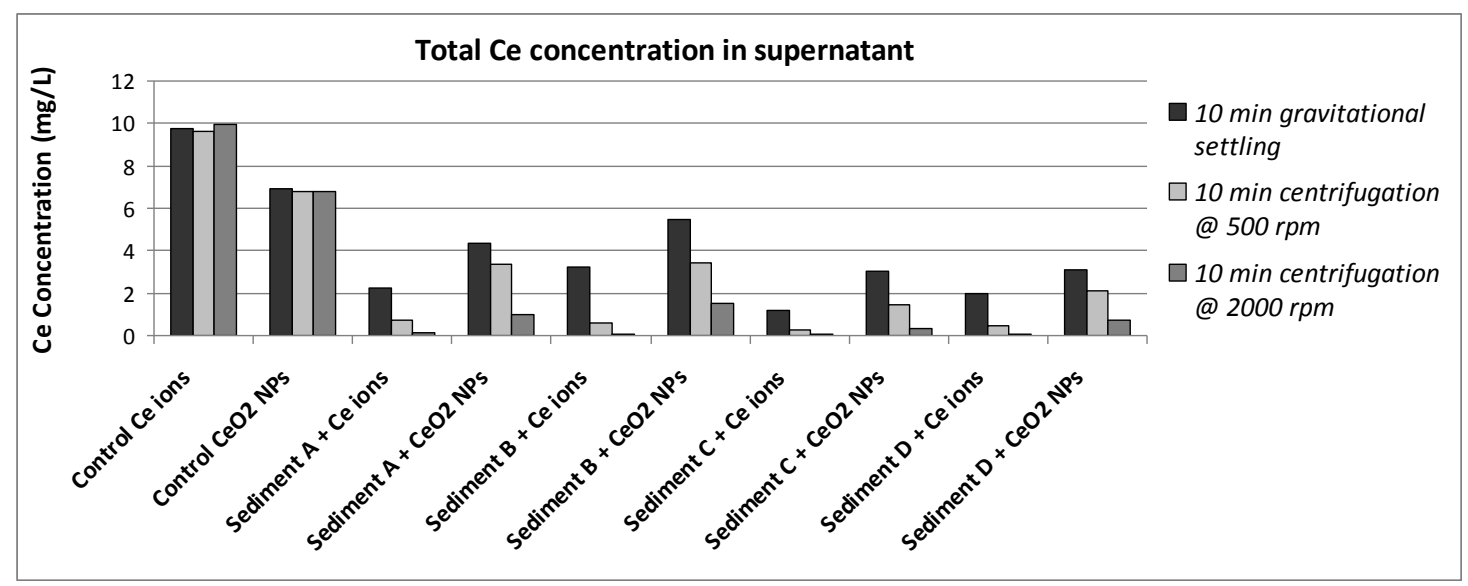

Figure 2. Cerium concentrations measured in the supernatant two hours after spiking the sediment suspensions with $\mathrm{CeO}_{2}$ nanoparticles (NPs) and $\mathrm{Ce}$ ions. Supernatants are obtained by subjecting the samples to 10 minutes of gravitational settling, or 10 minutes of centrifugation (at 500 and $2000 \mathrm{rpm}$, respectively). "Control Ce ions" and "Control $\mathrm{CeO}_{2} \mathrm{NPs}^{\mathrm{N}}$ refer to solutions spiked with same amounts of ions and NPs in absence of sediment.

\section{Acknowledgements}

The authors would like to thank Tewodros Tilahun and Gebeyehu Sebsibie for their efforts in experimental work and the Special Research Fund of Ghent University for provided financial support for conducting the research.

\section{References}

Darlington TK, Neigh AM, Spencer MT, Nguyen OT, and Oldenburg SJ. Nanoparticle characteristics affecting environmental fate and transport through soil. Environ. Toxicol. Chem. 2009; 28:1191-1199.

Fang J, Shan X, Wen B, Lin J, and Owens G. Stability of titania nanoparticles in soil suspension and transport in saturated homogeneous soil columns. Environ. Pol. 2009; 157:1101-1109.
Gimbert LJ, Hamon RE, Casey PS, and Worsfold PJ. Partitioning and stability of engineered $\mathrm{ZnO}$ nanoparticles in soil suspensions using flow field-flow fractionation. Environ. Chem 2007; 4:8-10.

Handy R, Owen R, and Valsami-Jones E. The ecotoxicology of nanoparticles and nanomaterials: current status, knowledge gaps, challenges and future needs. Ecotoxicology 2008; 17:315-325.

Van Ranst E, Verloo M, Demeyer A, and Pauwels JM. Manual for the soil chemistry and fertility laboratory: analytical methods for soil and plants equipment, and management of consumables. Ghent: University of Ghent, International Training Centre for Post-Graduate Soil Scientists; 1999. 243 p. 